\section{ROTOR DESIGN AND OPTIMIZATION OF SYNCHRONOUS RELUCTANCE MACHINE}

JAN BARTA, CESTMIR ONDRUSEK

Brno University of Technology

Faculty of Electrical Engineering and Communication Department of Power Electrical and Electronic Engineering Brno, Czech Republic

e-mail: xbarta27@stud.feec.vutbr.cz

The world has a bottomless appetite for electricity. Much of this electricity is used to power electric motors. Thanks to that electric motors represent a huge potential for energy savings. Synchronous reluctance machines are promising electric machines for energy savings. Key to success of synchronous reluctance machines is laying in elimination of rotor losses. This article deals with the design of synchronous reluctance machine of the transverse-laminated type. Rotor design has been made for two different rotor geometries based on general design recommendations. These geometries are studied and compared by using 2D finite element analysis. The geometries are developed by optimization algorithms after that. Optimized design is used for fabrication of synchronous reluctance machine. On fabricated synchronous reluctance machine several measurement and analysis of performance has been made. Finally fabricated synchronous reluctance machine is compared with induction machine with the same frame size.

KEYWORDS

synchronous reluctance machine, transverse-laminate rotor, electromagnetic model, finete element analysis, optimization,

torque ripple

\section{INTRODUCTION}

First reluctance machinery has been developed in 1920 but due to its low efficiency and poor torque characteristic it has not been further innovated for industrial purpose. These machines have found application mainly as drives for disks, tapes and printing heads.

Interest about synchronous reluctance machines having the same stator construction as induction machine can be dated to 1960. In the last years with technological development in power converters and with increasing requirements for saving of electrical energy this machine had become more interesting for industrial manufacturers. Conventional induction motors are still one of the least expensive industrial machines, but their further development is quite challenging. Due to that synchronous reluctance motors can in the future replace in some applications induction machine, at least as controlled drive systems.

There are three main types of synchronous reluctance machine rotors. The brief description of their historical development can be found in [Staton 1993]. The first one is rotor with salient poles. However, these rotors have poor properties to make them competitive in comparison with other alternative rotors. The second type of structure is axially laminated rotor. The rotor is formed from metal sheets which are shaped to create poles after assembling. These sheets are isolated from each other with suitable insulating material. The entire stack is then fixed to the inner part of the rotor, which is mounted on the shaft. The disadvantage of this solution is its technological difficulties in manufacture. Design and analysis of synchronous reluctance machine that uses this type of rotor is discussed in [Hrabovcova 2001] and [Sathyan 2003]. The last main type is transversely-laminated rotor (Fig. 1).
Air barriers cutted in rotor sheets include a narrow bridges that guarantee the mechanical strength of the rotor. The air barrier may be filled by epoxy to increase the mechanical strength of the rotor. Many papers deal with design of this kind of rotor geometry for example, [Kamper 1996], [Haataja 2003], [Reza 2007], [Matsuo 1994].

In this paper design of transverse-laminated rotor is discussed. This is due to obviously better structure of this rotor for industrial production. The geometry of transversely-laminated rotor may be punched into sheet all at once, like in case of an induction machine. Transverselaminated rotor sheets also can be easily skewed to reduce torque ripple, which is obviously very difficult for axially laminated rotor. On the other hand, stator stack can be skewed in case of axially laminated rotor, but the problem arises when we want to use the automatic retraction for the stator winding.

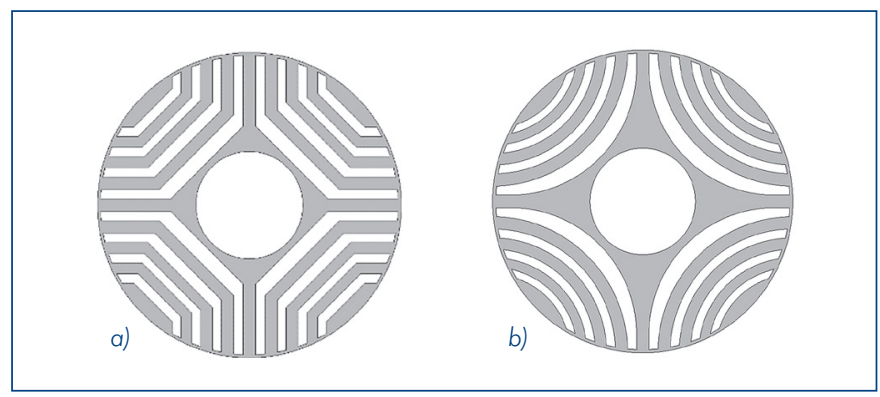

Figure 1. Transverse-laminated rotor

\section{METHOD OF DESIGN AND CALCULATION \\ 2.1 GOAL PARAMETERS}

Approximate relationship of the efficiency of synchronous reluctance machine shows [Reza 2007]. This relationship assumes that the joule losses in the stator windings are dominant with respect to other losses in the machine.

$$
\eta \approx\left(1+\frac{1}{\frac{\omega}{3 \cdot \mathrm{R}_{\mathrm{s}}} \cdot\left(\frac{\mathrm{T}}{\mathrm{I}_{\mathrm{s}}^{2}}\right)}\right)^{-1}
$$

where $\omega$ is angular velocity of the rotor, $R_{\mathrm{s}}$ is stator winding resistivity, $T$ is electromagnetic torque and $I_{s}$ is stator winding current. It can be seen from this relation that the efficiency increasing goal tends to increase of $\mathrm{T} / \mathrm{I}^{2}$ ratio. However, this relationship is valid only when the core losses and additional losses are negligibly small compared to the stator resistive losses.

The torque which is generated by the synchronous reluctance machine is not constant due to space harmonics in the air gap. Torque ripple creates some part of core losses, and therefore we cannot achieve maximum machine efficiency with optimization of rotor structure only with respect to the maximum average torque.

Core losses distribution in stator and rotor of standard induction machine is shown in Fig. 2a. Rotor core losses are small in comparison

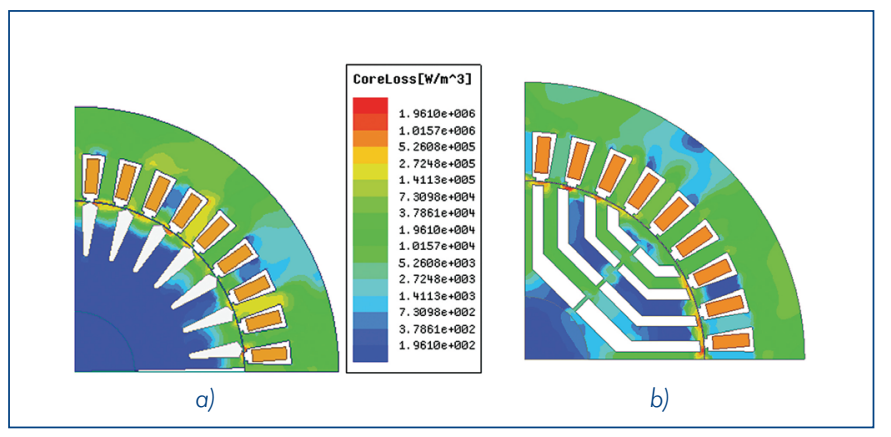

Figure 2. Core loss distribution a) induction motor b) SynRM 
with the stator one. Rotor core losses which are caused by changes in magnetic flux due to the stator slotting are concentrated around the outer perimeter. Inside the rotor core losses are minimal due to minimal changes in the magnetic flux density in time.

In comparison of synchronous reluctance machine with induction machine core losses in the rotor are presented more Fig. $2 b$. Depending on the geometry of the rotor they might be even comparable with the losses in the stator stack. The variation of magnetic flux in the individual barriers of rotor structure occurs due to the space harmonics in the air gap generated by slotted stator and also due to the anisotropic nature of the rotor, that interacts with a slotted stator [Reza 2007].

From the above it is assumed that in order to optimize the synchronous reluctance machine to achieve the best efficiency the reduction of torque ripple related to the reduction of core losses in the rotor stack must be taken into account as well as increase of the average torque

\subsection{ELECTROMAGNETIC DESIGN}

The main objective of this article is to design synchronous reluctance machine that is powered from a symmetrical 3-phase, $400 \mathrm{~V}, 50 \mathrm{~Hz}$ power supply line. The stator winding of synchronous reluctance machine will be connected in D.

For simplification of the design process stator is taken from standard $2.2 \mathrm{~kW}$ cage induction machine. Fig. 3 shows machine dimensional drawing. Since the stator dimensions are fixed, the rotor design remains. Low torque ripple design of rotor structure is described in [Vagati 1998]. This paper is focusing on finding relation between number of rotor barriers and stator slots. The number of stator slots can be defined by

$$
\mathrm{N}_{\mathrm{S}}=\mathrm{n}_{\mathrm{s}} \cdot \mathrm{p}=6 \cdot \mathrm{q} \cdot \mathrm{p}
$$

where $n_{s}$ is number of stator slots per pole-pair, $p$ is number pole-pairs, $q$ is number of slots per pole and phase. It is assumed at [Vagati 1998] that stator slots are magnetically opened, since there are not magnetic wedges. Bridges which are connecting each layers of rotor structure are saturated so they are considered like magnetically opened too. Thanks to that some interaction between rotor and stator slotting is generated.

The paper [Vagati 1998] shows that a complete analysis of this phenomena is very difficult. However, studies of this problem concluded that the number of rotor slots should respect following relation

$$
\begin{gathered}
\mathrm{n}_{\mathrm{s}}-\mathrm{n}_{\mathrm{r}} \neq 0,+2,-2 ; \mathrm{n}_{\mathrm{r}}>6 \\
\mathrm{n}_{\mathrm{s}}-\mathrm{n}_{\mathrm{r}}= \pm 4
\end{gathered}
$$

where $n_{r}$ is number of rotor slots per pole-pair. Also, in order to achieve the minimum torque ripple, in paper [Vagati 1998] it is recommended

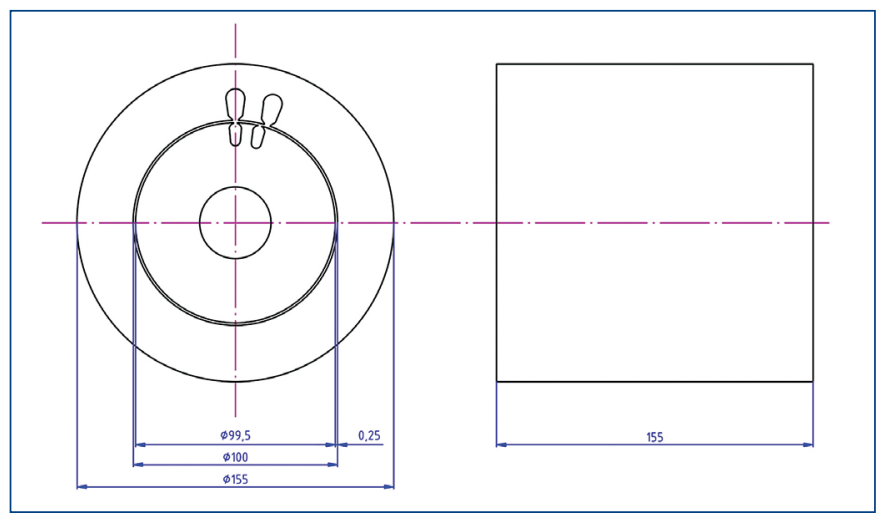

Figure 3. Induction machine dimensional drawing used for design of synchronous reluctance machine that rotor layers should have a constant permeance, which mean that a ratio between length and width of each rotor layer should be nearly equal for all the rotor layers, in order to avoid producing harmonics capable of interacting with harmonics produced by stator.

In design process presented in this paper we are limited by options of electromagnetic parametrical model (see part 2.3). Since assumed stator has 36 slots the resultant reluctance rotor should have 22 or 14 rotor slots per pole-pair (for justification see equation (4)). In practice, this means that the rotor 18/14 (18 stator slots per pole-pair/14 rotor slots per pole pair) will have three barriers and rotor 18/22 will have four barriers. For these geometries, with respect to general design recommendation [Vagati 1998], initial design has been made.

\subsection{ELECTROMAGNETIC MODEL}

Operation of electrical machines and other electromechanical devices is based on the energy conversion from the electromagnetic field. Therefore, the analysis of these devices is based on the solution of these fields or their approximations. For solving the electromagnetic fields in analyzed problem finite element time-stepping 2D method is used. It belongs to category of numerical methods.

Only one pole pitch has been modeled and discretized. Periodic boundary conditions have been used at the radial boundaries of the problem region. For purpose of optimization fully parametrical model of synchronous reluctance machine has been used. These parametrical models realizing rotor geometries are shown in Fig. 1.

Barrier ideal parametric model should allow quite arbitrarily change of its shape. Each barrier is composed from discreet points which are connected by straight lines. We can model the desired ideal shape by changing the positions of these points in a $2 \mathrm{D}$ space. Each point represents a variable which is considered in optimization. Since optimization of the barrier shape is time consuming process we have to work with the lowest number of connected points in the 2D plane. Such points are connected by predefined geometric shapes.

For maintaining a constant permeance of magnetically conductive segment we require expansion of the barrier in q-axis. Rotor geometry consisting only of the barriers illustrated in Fig. $4 \mathrm{~b}$ which is composed from 4 points in a 2D plane is not acceptable. Fig. 4 a shows a barrier that is created by six points in the 2D plane. Six points are connected by straight lines and two arcs. Barrier defined like this, allow expansion in q-axis by changing the parameter " $k 1$ ".

The resulting parametric model is consisted from barriers, where the first is barrier formed by the geometry illustrated in Fig. 4a, and any other barrier formed by the geometry in Fig. 4b. Example of assembled rotor of such defined elements is shown in Fig. 1b. Rotor made up of these barriers will be referred to as round.

Second parametric model of assembled rotor consist of angular barriers, as in Fig. 4c. These angular barriers consist of 8 interconnected points in 2D plane. Rotor made up from these barriers will be referred to as angular, Fig la.

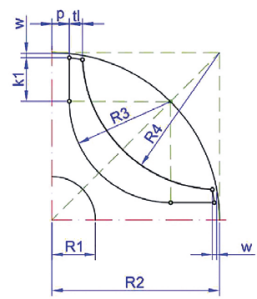

a)

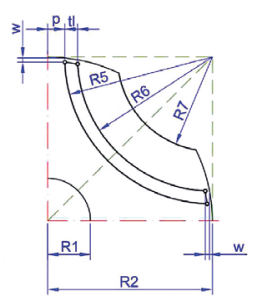

b)

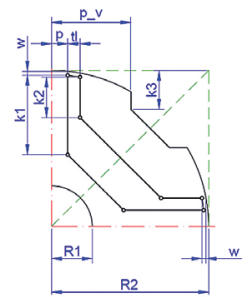

c)
Figure 4. Drawings of rotor parametrical models 


\subsection{METHOD OF ANALYSIS}

Machine running at constant speed and with constant load torque is considered during calculation. Stator windings are powered by sinusoidal current with a constant amplitude. For these currents we can write following equations

$$
\begin{gathered}
\mathrm{i}_{\mathrm{A}}=\mathrm{I}_{\max } \cdot \sin (\omega \cdot \mathrm{t}+\varphi) \\
\mathrm{i}_{\mathrm{B}}=\mathrm{I}_{\max } \cdot \sin \left(\omega \cdot \mathrm{t}-\frac{2 \cdot \pi}{3}+\varphi\right) \\
\mathrm{i}_{\mathrm{C}}=\mathrm{I}_{\max } \cdot \sin \left(\omega \cdot \mathrm{t}+\frac{2 \cdot \pi}{3}+\varphi\right)
\end{gathered}
$$

where $i_{A^{\prime}} i_{B^{\prime}} i_{C}$ are currents of each phase, $\varphi$ is phase shift, and $I_{\max }$ is calculated from rated current of studied electrical machine.

$$
\mathrm{I}_{\max }=\frac{\sqrt{2}}{\sqrt{3}} \cdot \mathrm{I}_{\Delta}
$$

where $I_{\Delta}$ is rated current for delta connection of origin induction machine. Simulation is further configured so that the electromagnetic torque calculation runs in the 15 mechanical degrees with spacing by 1 mechanical degree. This spacing corresponds to $3 / 2$ of the slot pitch [Hudak 2006]. Such setup make calculation time relatively short and also giving sufficient result for purpose of performed optimization (see part 2.5). The initial position of the rotor is set according to Fig. 5 and the currents have initial phase shift $\varphi=\pi / 2$. This situation corresponds to zero load angle. Load angle can be varied by changing of phase shift.

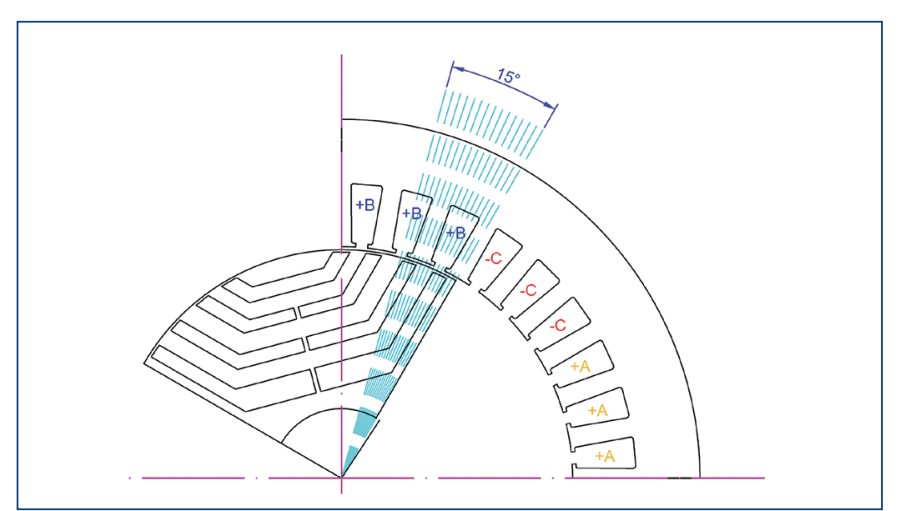

Figure 5. Rotor moving during torque calculation

\subsection{METHOD OF OPTIMIZATION}

Optimization is performed by using genetic algorithm (GA) and pattern search (PS). These algorithms are briefly described in the [Kurfürst 2014]. Optimization is performed only for type 18/22. The 18/14 type is not included in the optimization (see justification in next chapter). Concepts of optimization and kind of optimization algorithms are discussed in [Kurfürst 2014]. The practical application of optimization in field of electrical machines can be find in [Zelinka 2002]. Cost function is the function whose minimization leads to finding the optimal values of its arguments. In this paper cost function based on [Kurfürst 2014 ] is used in the following format

$$
\text { Cost }=\left(\frac{T_{C \text {-avg }}}{T_{b-\text { avg }}}-\frac{T_{R \text {-avg }}}{T_{b \text {-avg }}}\right)^{2} \cdot \mathrm{W}_{1}+\left(\frac{T_{C \text {-ripple }}}{T_{b-\text { ripple }}}-\frac{T_{R-\text { ripple }}}{T_{b-\text { ripple }}}\right)^{2} \cdot \mathrm{W}_{2}
$$

where $T_{C \text {-avg }}$ is calculated average value of torque, $T_{R \text {-avg }}$ is required average value of torque, $T_{C \text {-ripple }}$ is calculated torque ripple, $T_{\text {R-riple }}$ is required torque ripple, $T_{\text {b-avg }}$ is reference average value of torque $T_{\text {b-ripple }}{ }^{\text {-ripple }}$ is reference torque ripple. Coefficients determining the priority optimization are marked as $\mathrm{W}$.

Optimization goals are $T_{\text {R-avg }}=20 \mathrm{Nm}$ and $T_{\text {R-ripple }}=10 \%$. The weight coefficients are chosen as $W_{1}=1$ and $W_{2}=2$. This setting is giving a higher priority to optimization of torque ripple. The objective function (9) is then entered into Ansoft Maxwell software.

The aim of cost function is to express values in relative magnitudes. It has been shown in [Kurfürst 2014] that relative magnitudes have great advantage because already during the creation of the optimization problem it is obvious which argument will be dominating and vise versa. In defined cost function optimization algorithms will search for a local minimum.

\section{CALCULATION RESULTS \\ 3.1 INITIAL DESIGN}

Fig. 6a shows that the calculated dependence of the average torque on the rotor load angle for initially designed geometries are almost the same. Their maximum values are listed in Table. 1. Torque ripple is calculated from the following equation

$$
\mathrm{T}_{\text {ripple }}=\frac{\mathrm{T}_{\text {max }}-\mathrm{T}_{\text {min }}}{\mathrm{T}_{\text {avg }}} \cdot 100
$$

where $T_{\max }$ is maximum value of torque in investigated time interval, $T_{\min }$ is minimum value of torque in investigated time interval and $T_{\text {avg }}$ is average value of torque.

Fig. $6 \mathrm{~b}$ shows calculated dependence of torque ripple at the load angle. From these waveforms it can be seen that the relative size of torque ripple related to the average torque decreases with increasing load angle. It can be seen from comparing of each geometry that the geometry of the type 18/14 produces torque ripple significantly higher than geometry $18 / 22$.

Furthermore, it is evident from Fig. $6 \mathrm{~b}$ that the geometry of the same number but different barriers shape have almost identical values of torque ripple. For lower loading angles is a little bit better geometry with a round shape barriers. Numerical comparisons between the rotors, for load angle $55^{\circ}$ is presented in Table 1.

\begin{tabular}{|c|c|c|}
\hline Rotor type & Average torque $\mathbf{( N m})$ & Torque ripple (\%) \\
\hline $18 / 22$ round & 17.22 & 13.02 \\
\hline $18 / 14$ round & 17.12 & 28.68 \\
\hline $18 / 22$ angular & 16.16 & 15.20 \\
\hline $18 / 14$ angular & 16.91 & 26.46 \\
\hline
\end{tabular}

Table 1. Values of observed parameters for load angle $55^{\circ}$

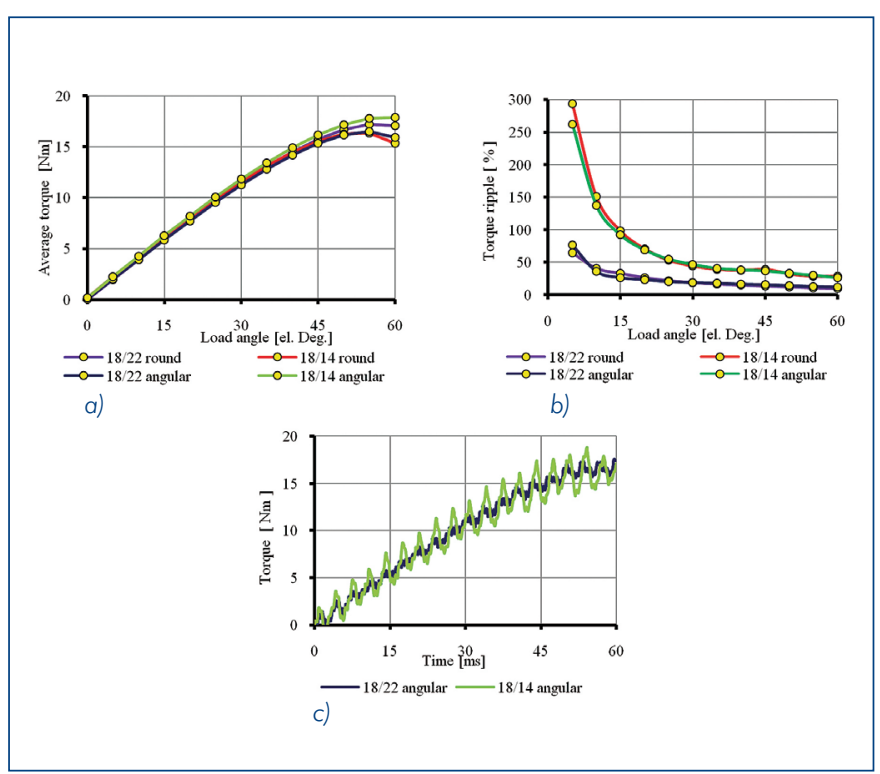

Figure 6. a) Average torque dependence on load angle b) Torque ripple dependence on load angle c) Torque characteristics of angular rotor (Note: in every single millisecond the load angle is inceased by 1 el. Deg.) 


\subsection{OPTIMIZED DESIGN}

During optimization the dimensions of parametric model are change Example of difference before and after optimization can be seen at Fig. 7. The optimization results for observed parameters are shown in Table 2. Parameters before optimization are also include in columns "Orig".
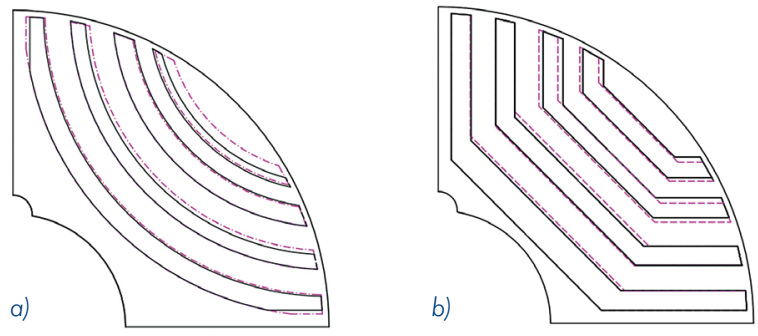

Figure 7. a) Initial $18 / 22$ round rotor geometry (dashed line) and refined by GA (solid line) b) Initial 18/22 angular rotor geometry (dashed line) and refined by GA (solid line)

In a round geometry optimization carried out with GA reduces torque ripple approximately by $27 \%$ and with the PS by $25 \%$. Average value of torque has been reduced by $0.11 \%$ in case of using GA and by $1.68 \%$ in case of using PS in optimized round geometry.

In a angular geometry optimization carried out with GA reduces torque ripple approximately by $53 \%$ and with the PS by $49 \%$. Average value of torque has been reduced by $1.8 \%$ in case of using GA and by $134 \%$ in case of using PS in optimized round geometry.

By comparing values before and after optimization it can be concluded that optimization lead to some reduction of average torque, as well as significant reduction of the torque ripple.

\begin{tabular}{|c|c|c|c|}
\hline \multicolumn{1}{|c}{ Rotor type } & $\begin{array}{c}\text { Average torque } \\
(\mathbf{N m})\end{array}$ & $\begin{array}{c}\text { Torque ripple } \\
(\%)\end{array}$ \\
\hline \multirow{2}{*}{ GA 18/22 round } & Orig & 17.22 & 13.02 \\
\cline { 2 - 4 } & Opti & 17.20 & 9.48 \\
\hline \multirow{2}{*}{ PS 18/22 round } & Orig & 17.22 & 13.02 \\
\cline { 2 - 4 } & Opti & 16.93 & 9.75 \\
\hline \multirow{2}{*}{ GA 18/22 angular } & Orig & 17.16 & 15.20 \\
\cline { 2 - 4 } & Opti & 16.85 & 7.06 \\
\hline \multirow{2}{*}{ PS 18/22 angular } & Orig & 17.16 & 16.93 \\
\cline { 2 - 4 } & Opti & 15.20 & 7.63 \\
\hline
\end{tabular}

Table 2. Comparation of observed parametrs after and before optimatization for load angle $55^{\circ}$

\subsection{OPTIMIZED DESIGN WITH SKEWED ROTOR STACK}

By skewing of rotor stack further reduction of torque ripple can be achieved. Method described in [Bomela 2002] for analysis of skewing by 2D finite element analysis is used. According to this metod, skewing can be represented by using a set of unskewed machines of which the rotors are relatively displaced by an angle that is a fraction of the total skew. Current is the same for each set of unskewed machines but load angle and inductances are different.

Five submachines have been used for skewing analysis. Calculated results for optimized design GA 18/22 angular are shown at Fig. 8. It can be seen that by skewing of rotor by 1.2 times of stator slot pitch the lowest torque ripple is achieved. Compared to original one the torque ripple is reduced by $67.87 \%$ at this skew angle. Average value of torque is reduced by $2.3 \%$. It can be concluded that skewing of rotor leads to significant reduction of torque ripple in designed synchronous reluctance machine.

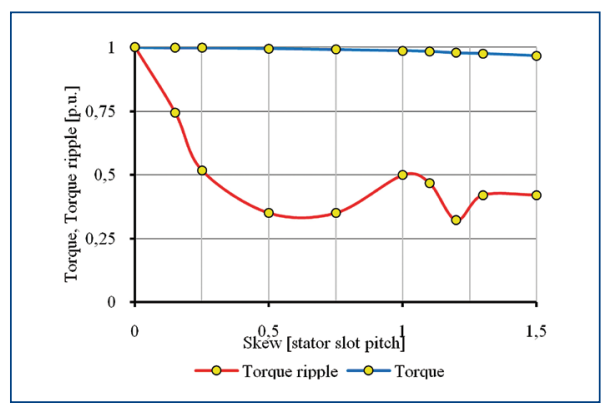

Figure 8. Effect of skew on per-unit torque and torque ripple for load angle 45 el. deg. (GA 18/22 angular)

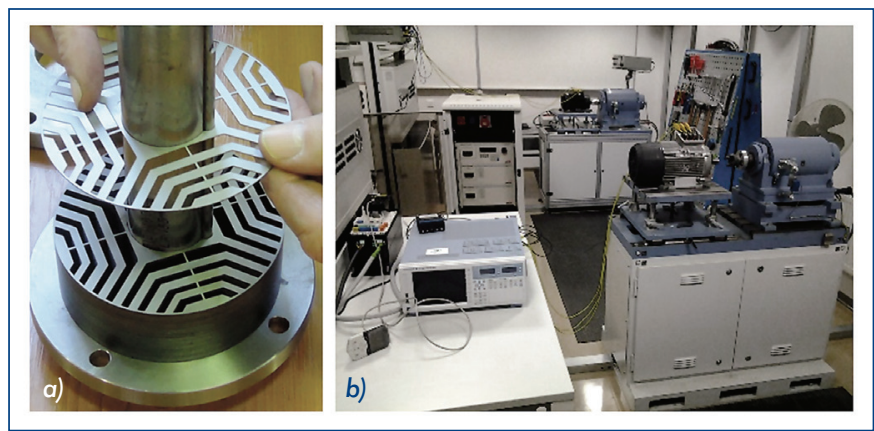

Figure 9. a) Assembly of transverse-laminated rotor core b) Measuring workplace

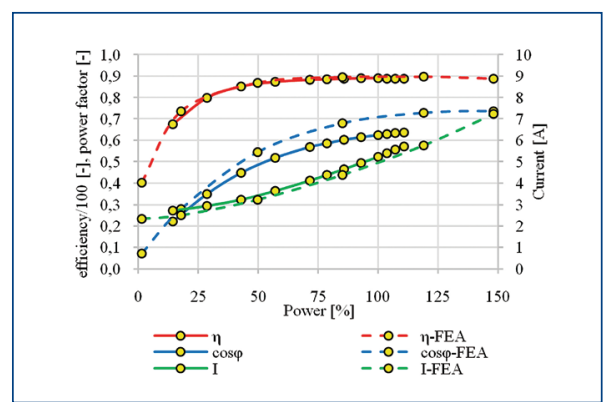

Figure 10. Load characteristic of synchronous reluctance machine

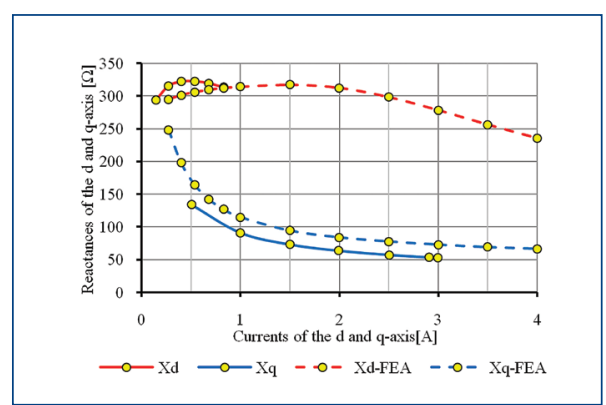

Figure 11. The dependency of synchronous reactances on $d$ and $q$-axis currents

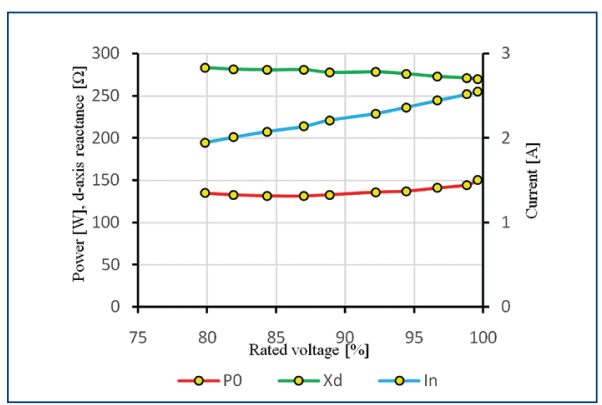

Figure 12. No-load characteristics of synchronous reluctance machine 


\section{MEASURED RESULTS ON MACHINE PROTOTYPE}

Optimized rotor type 18/22 has been used for manufacturing. The original rotor of $2.2 \mathrm{~kW}$ induction machine has been replaced by assembled transverse-laminated rotor. Barriers in the rotor structure are cut off by using laser technology. Some basic measurements on such manufactured motor has been made. Scalar-controlled inverter for machine running has been used. Frequency invertor regulators has to be set up appropriately to avoid instability while running of synchronous reluctance machine.

In Fig. 10 measured load characteristics and calculated by finite element analysis are compared. In Fig. 11, the measured dependences of direct and quadrate axis reactances are shown. Calculated by finite element analysis dependences are marked as FEA. There is some difference between calculated and measured values, this may be caused by manufacturing technology of the rotor. Real surface diameter of the rotor is little bit smaller that should be, also some degradation of magnetic core properties may be expected since laser technology is used [Emura 2003]. Measurement results during the no-load condition are shown in Fig. 12. The synchronous reluctance machine becomes unstable below the $80 \%$ of rated voltage.

Finally comparison of induction machine with designed synchronous reluctance machine for rated load condition is shown in Table 3. Designed synchronous reluctance machine have poorer power factor than initial induction machine. This is caused by inaccuracy during the manufacturing process when the air gap of reluctance machine is somehow larger than induction machine one. Expected power factor for case when the air gap is the same as in induction machine is 0.77 (value is obtained by finite element analysis). Designed synchronous reluctance machine is better than initial induction machine from efficiency point of view.

\begin{tabular}{|c|c|c|}
\hline \multicolumn{2}{|c|}{$\begin{array}{c}\text { Initial } \\
\text { induction machine }\end{array}$} & $\begin{array}{c}\text { Synchronous } \\
\text { reluctance machine }\end{array}$ \\
\hline Stator current [A] & 4,4 & 5,23 \\
\hline Power [W] & \multicolumn{2}{|c|}{2200} \\
\hline Power factor [-] & 0,83 & 0,62 \\
\hline Efficiency [\%] & 86,7 & 89 \\
\hline
\end{tabular}

Table 3. Initial induction machine comparation with designed synchronous reluctance machine

\section{CONCLUSION}

Analytical design of rotors with different shapes and number of barriers has been discussed. The stator of standard induction machine has been used. By analysis of the analytically designed geometries, it has been found that all proposed rotors have almost the same dependence of average torque on the load angle, but significantly different torque ripple for different number of barriers. With the same number of barriers, but a different shape of barrier torque ripple did not differ significantly. It can therefore be assumed that the most essential effect on the parameters of the machine has the correct choice of the number of barriers, which may vary depending on the number of stator slots. For 36 stator slots use of a rotor with four barriers was found to be most advantageous. By applying the design principles given in [Vagati 1998] a rotor structure can be relatively quickly designed.

The proposed four barrier geometry, which proved analytically proposal as the best, were further modified by using optimization algorithms. The optimization is focused on increasing average value of torque and torque ripple reduction, which has a major impact on the losses in the rotor core. The optimized geometry compared with analytically designed geometries have lower torque ripple, in some cases up to $50 \%$.

Further reduction of torque ripple can be achieved by skewing of rotor slots. It was found that skewing by 1.2 times of stator slot pitch can reduce torque ripple approximately up to $68 \%$.

Optimized geometry has been used for prototype manufacture. By measurement on motor prototype has been found some differences between expected and calculated performance of machine. It is assumed that these differences are caused by used technology of manufacturing process.

It can be concluded that design of synchronous reluctance machine is relatively complex matter. This article focuses only on optimal electromagnetic rotor design of the machine. Nevertheless designed machine has higher efficiency than induction machine in the same frame size. On the other hand due to poorer power factor more current is consumed by synchronous reluctance machine.

\section{ACKNOWLEDGMENT}

This research, performed in the Centre for Research and Utilization of Renewable Energy, was supported by the Ministry of Education, Youth and Sports under project No. LO1210 of National Programme for Sustainability 1 .

\section{REFERENCES}

[Bomela 2002] Bomela, B. and Kamper, J. Effect of Stator Chording and Rotor Skewig on Performance of Reluctance Synchronous Machine. Industry Applications, January 2002, Vol. 38, No. 1., pp 91-100

[Emura 2003] Emura M. et. al. The influence of cutting technique on the magnetic properties of electrical steels. Journal of Magnetism and Magnetic Materials, January 2003, pp 358-360

[Haataja 2003] Haataja J. A comparative performance study of fourpole induction motors and synchronous reluctance motors in variable speed drives. Doctoral thesis. Lappeenranta: Lappeenranta University of Technology, (2003)

[Hrabovcova 2001] Hrabovcova V. Synchronous reluctance machine. Zilina: EDIS, 2001. ISBN 80-7100-891-5 (in Slovak)

[Hudak 2006] Hudak P. and Hrabovcova V. Geometrical dimension influence of multi-barrier rotor on reluctance synchronous motor performances. International Symposium on Power Electronics, Eletrical Drives, Automation and Motion SPEEDAM, May 2006, pp 346-351

[Kamper 1996] Kamper M. J. et al. Direct finite element design optimization of the cage less reluctance synchronous machine. Energy Conversion, Sept. 1996, Vol. 11, No. 3., pp 547-55

[Kurfürst 2014] J. Kurfürst. Optimization of the permanent magnet machine based on the artificial inteligence. Doctoral thesis. Brno: Brno University of Technology, 2014 (in Czech)

[Matsuo 1994] Matsuo T. and Lipo T. A. Rotor design optimization of synchronous reluctance machine. Energy Conversion, June 1994, Vol. 9, No. 2., pp 359-365

[Reza 2007] Reza M. Synchronous Reluctance Machine (SynRM) Design. Master thesis. Stockholm: Royal Institute of Technology, 2007

[Sathyan 2003] Sathyan S. Synchronous reluctance motor for household applications. Master thesis. Espoo: Aalto university, 2003

[Staton 1993] Staton D. A. et al. Maximising the Saliency Ratio of the Synchronous Reluctance motor. IEE PROCEEDINGS-B, July 1993, Vol. 140, No. 4., pp 249-259

[Vagati 1998] Vagati A. et al. Design of low-torque-ripple synchronous reluctance motors. Industry Applications, July 1998, Vol. 34, No. 4., pp 758-765.

[Zelinka 2002] Zelinka, I. Artificial Intelligence in global optimization problems. Praha: BEN, 2002. ISBN 80-7300-069-5 (in Czech)

\section{CONTACTS}

Ing. Jan Barta

tel.: +420 541146 759, e-mail: xbarta27@stud.feec.vutbr.cz doc. Ing. Cestmir Ondrusek, CSc.

tel.: +420541 146 717, e-mail: ondrusek@feec.vutbr.cz

Brno University of Technology

Faculty of Electrical Engineering and Communication

Department of Power Electrical and Electronic Engineering

Technicka 10, 61600 Brno, Czech Republic

www.vutbr.cz 